\title{
O ENSINO DA ÉTICA E DA BIOÉTICA NO PROCESSO DE FORMAÇÃO DO ENFERMEIRO FRENTE ÀS DIRETRIZES CURRICULARES NACIONAIS
}

Janieiry Lima de Araújo ${ }^{1}$, Maria Salete Bessa Jorge ${ }^{2}$, Consuelo Helena Aires de Freitas ${ }^{3}$, Thereza Maria Magalhães

Moreira ${ }^{4}$

RESUMO: Reflexão teórica do ensino da ética/bioética na graduação em enfermagem no Brasil, caracterizada por visão deontológica. O objetivo é refletir sobre o ensino da ética/bioética e as Diretrizes Curriculares Nacionais em Enfermagem. Foi feito estudo bibliográfico na Biblioteca Virtual em Saúde e outros referenciais sobre o tema em questão. Os resultados encontrados apresentam-se como desafio aos processos de formação em enfermagem e pauta de reflexão/ação do ensino da ética na enfermagem: formação/capacitação docente na área; transversalidade da ética no Projeto Pedagógico do Curso; definição do marco teórico-conceitual, com base no saber interdisciplinar; articulação dos conteúdos disciplinares da enfermagem com os problemas práticos; adoção de métodos/estratégias de ensino problematizadoras e participação ativa dos atores no processo de formação. Pensar a prática docente voltada à incorporação dos saberes da ética/bioética frente às diretrizes demanda romper as concepções tradicionais da ética ao campo normativo da moral humana e capacitar os professores nesse campo.

PALAVRAS-CHAVE: Ética; Bioética; Currículo; Educação em enfermagem.

\section{THE TEACHING OF ETHICS AND BIOETHICS IN THE NURSES' FORMATION PROCESS REGARDING THE NATIONAL CURRICULUM GUIDELINES}

\begin{abstract}
Theoretical reflection of the teaching of ethics/bioethics in undergraduate nursing programs in Brazil, by the ethical point of view. The objective is to reflect about the teaching of ethics/bioethics and the National Curricular Guidelines in Nursing. We studied literature in the Virtual Health Library and other references on the subject in question. The results show up as a challenge to procedures for training nursing and the reflection/action of the teaching of ethics in nursing: teacher training in the area; transversality of ethics in the Course Educational Project; definition of the conceptualtheoretical framework, based on interdisciplinary knowledge, articulation of disciplinary content of nursing with practical problems, adoption of problematizing methods/strategies; education and active participation of actors in the process of training. Thinking about the teaching practice focused on the incorporation of knowledge of ethics/bioethics regarding the guidelines requires the breaking up with the traditional conceptions of normative ethics to the field of human moral and training of teachers in this field.
\end{abstract}

KEYWORDS: Ethics; Bioethics; Curriculum; Education, nursing.

\section{LA ENSEÑANZA DE LAÉTICAY DE LA BIOÉTICA EN EL PROCESO DE FORMACIÓN DEL ENFERMERO FRENTE A LAS DIRECTRICES CURRICULARES NACIONALES}

RESUMEN: Reflexión teórica de la enseñanza de la ética/bioética en la graduación en enfermería en el Brasil, caracterizada por una visión deontológica. El objetivo es reflexionar sobre la enseñanza de la ética bioética y las Directrices Curriculares Nacionales en Enfermería. Fue hecho un estudio bibliográfico en la Biblioteca Virtual en Salud y otros referenciales sobre el tema en cuestión. Los resultados encontrados se presentan como desafío a los procesos de formación en enfermería y pauta de reflexión/acción de la enseñanza de la ética en enfermería: formación/capacitación docente en el área; transversalidad de la ética en el Proyecto Pedagógico del Curso, definición del marco teórico-conceptual, con base en el conocimiento interdisciplinar; articulación de los contenidos disciplinares de enfermería con los problemas prácticos, adopción de métodos/ estrategias de enseñanza problematizadoras y participación activa de los actores en el proceso de formación. Pensar la práctica docente direccionada hacia la incorporación de los conocimientos de la ética/bioética frente a las directrices, requiere las concepciones tradicionales de la ética al campo normativo de la moral humana y capacitar a los profesores en ese campo. PALABRAS CLAVE: Ética; Bioética; Currículo; Educación en enfermería.

\footnotetext{
${ }^{1}$ Docente de Enfermagem. Universidade do Estado do Rio Grande do Norte-UERN. Mestranda do Curso de Mestrado Acadêmico em Cuidados Clínicos em Saúde-CMACCLIS. Universidade Estadual do Ceará-UECE.

${ }^{2}$ Doutora em Enfermagem. Docente do CMACCLIS-UECE. Coordenadora do Curso de Mestrado Acadêmico em Saúde PúblicaCMASP-UECE.

${ }^{3}$ Doutora em Enfermagem. Docente do CMACCLIS-UECE.

${ }^{4}$ Doutora em Enfermagem. Docente do CMACCLIS-UECE.
}

Autora correspondente:

Janieiry Lima de Araújo

Rua José Ferreira da Costa, 41 - 59900-000 - Pau dos Ferros-RN

Recebido: 13/02/09

E-mail: janieiry@hotmail.com

Aprovado: 10/09/09 


\section{INTRODUÇÃO}

O ensino da ética e da bioética nos cursos de graduação em enfermagem no Brasil se caracteriza por visão deontológica, um reducionismo, uma vez que esse normativismo cede ao dogmatismo ético. A educação ética/bioética somente fundamentada em discussões conceituais e normativas não tem sido suficiente para formar enfermeiros críticos e reflexivos capazes de tomar decisões de ordem técnica, científica, social e ética nas situações relacionadas ao desenvolvimento científico e tecnológico e nos conflitos persistentes e emergentes vivenciados na diversidade moral e cultural dos indivíduos e coletivos ${ }^{(1-2)}$. Vivemos num mundo imenso em convulsão, no qual valores morais balizadores das estruturas de equilíbrio sóciocultural estão em desuso ou sendo questionados ${ }^{(3)}$.

Diante dessa realidade, as escolas de enfermagem se esforçam para redimensionar a prática docente da ética/bioética, contemplando os aspectos filosóficos, sociais e psicopedagógicos do educador, com o objetivo de facilitar a reflexão e a aplicação destes conhecimentos no processo de formação da enfermagem, promovendo assim a adesão dos cursos de graduação às Diretrizes Curriculares Nacionais$\mathrm{DCN}^{(4)}$

O debate proposto neste estudo aponta para a incorporação dos saberes múltiplos da eticidade presentes num mundo atual. Mundo onde situações conflitantes no campo da bioética ainda persistem e outras situações intrínsecas das relações humanas emergem. A solução encontra-se além do saber técnico-científico de caráter tradicionalmente normativo. Portanto, trabalhar essa área do conhecimento demanda a reorientação conceitualmetodológica utilizada na docência, a redefinição das metodologias de ensino e a adoção de atitudes no ensino da ética dos futuros profissionais da saúde, em especial, dos enfermeiros.

Este texto, portanto, é uma reflexão teórica sobre o ensino da ética e da bioética nos cursos de graduação em enfermagem. Como referencial teórico utilizou artigos, livros, textos jurídicos sobre a educação/formação em enfermagem e a prática profissional da enfermagem (resoluções, leis etc.) e outros sobre a história da enfermagem e das políticas de saúde no Brasil. A análise dos resultados consistiu na fase de interpretação e esta ocorreu a partir da leitura crítica do referencial bibliográfico selecionado para este estudo ${ }^{(7-8)}$.

Assim, este artigo representa uma aproximação teórica com a temática em discussão e tem por objetivo refletir sobre o ensino da ética e da bioética frente às Diretrizes Curriculares Nacionais da Enfermagem.

\section{RESGATE DAS PRÁTICAS CURRICULARES NO ENSINO DE ENFERMAGEM NO BRASIL}

O ensino de enfermagem no país passou por fases de desenvolvimento ao longo dos anos, tendo como reflexo de cada mudança o contexto histórico da enfermagem e da sociedade brasileira. As mudanças curriculares partiram das necessidades impostas pelas transformações sociais, econômicas e políticas no Brasil e no mundo. Historicamente o ensino sistematizado da Enfermagem no Brasil foi introduzido pelo Decreto $n^{\circ} .16300 / 23$, no Rio de Janeiro, mediante a organização do Serviço de Enfermeiras do Departamento Nacional de Saúde Pública-DNSP, então dirigida por Carlos Chagas e, posteriormente, denominada Escola de Enfermagem Anna Nery ${ }^{(6)}$.

$O$ ensino de enfermagem então surge conjuntamente às práticas sanitárias do modelo sanitarista de produção de serviços de saúde dos portos e das cidades. O Brasil vivia o modo capitalista de produção, exigindo que as escolas polarizassem o ensino, do mais simples ao mais complexo, fato que consequentemente gerou a dicotomia entre o saber e o fazer da enfermagem ${ }^{(9)}$. Reforçando, assim, a divisão do trabalho intelectual e manual.

Nessa fase, o debate sobre a prática curricular do ensino polarizante, tradicionalmente presente nas escolas capitalistas, é o foco da atenção dos educadores da área ${ }^{(9)}$. O fato educacional gerou a ideia dicotômica entre o conhecimento produzido nas instituições de ensino - visto como local onde a ciência é produzida. Nesse espaço o pensamento transformase em teoria e as pessoas que ali se encontram, em detentores do saber. E o conhecimento produzido pelo trabalho realizado nas instituições prestadoras de cuidados de saúde - visto como o local onde a prática é produzida. Nesse espaço o trabalho manual é considerado algo desqualificado e as pessoas que ali se encontravam - os trabalhadores braçais, detentoras de um saber mecânico, técnico e rotineiro.

Um estudo anterior ${ }^{(6)}$ aponta como comprovação desse fato os resultados da análise dos currículos de formação em enfermagem da época. Seus conteúdos, disciplinas e correspondentes cargas horárias eram, em sua maioria, direcionadas ao ensino de enfermagem para a atenção hospitalar e o cuidado individual. Assim, a 
década de 50 se caracterizou pelo intenso debate sobre a exigência para o ingresso nos cursos de enfermagem do secundário completo; medidas prorrogaram o tempo para a conclusão do curso nos anos de 1956 e 1962. O temor era de que os requisitos de admissão, considerados rígidos, pudessem diminuir a procura pelas escolas de enfermagem e, consequentemente, a formação do futuro corpo docente. Os contrários à prorrogação do tempo e à não-exigências de escolaridade mínima argumentavam que a adoção de critérios mais sistemáticos era feita pensando exclusivamente na melhoria da qualidade do ensino( ${ }^{(9)}$.

Analisando a história do ensino em enfermagem, fatos revelam que as práticas curriculares em 1923, 1949, 1962 e 1972 eram voltadas para a "formação do enfermeiro [...], centrada no pólo indivíduo/doença/cura e na assistência hospitalar, seguindo o mercado de trabalho específico de cada época"(6:571). Observa-se na década de 60 o investimento governamental na formação de técnicos de enfermagem em nível médio, o que se traduz pela concepção da divisão técnica do trabalho de enfermagem. "Sua argumentação baseiase na larga faixa de atribuições que não eram atendidas, [...] nem pelos auxiliares, por falta de preparo, e nem por enfermeiras, devido ao pequeno número" ${ }^{(9: 84)}$.

Através do Parecer nº. 271/62 é estabelecido o currículo mínimo, passando a enfermagem a ser considerada ensino de nível superior, mas mantendo-se os níveis elementares de formação: auxiliar, de nível fundamental e técnico, de nível secundário completo. Em 1968, a reforma universitária proposta pelo Conselho Federal de Educação determina a revisão dos currículos mínimos dos cursos superiores ${ }^{(10)}$. Em 1972, o Parecer n ${ }^{\circ}$. 163/72 aprova o currículo mínimo do Curso de Enfermagem e Obstetrícia, com a duração de três a cinco anos. Essa modificação curricular permitiu que a enfermeira formada se habilitasse e se especializasse em áreas de atuação distintas e privativas aos egressos do nível superior de formação: obstetrícia, saúde pública, médico-cirúrgica e/ou licenciatura ${ }^{(10)}$. Ainda nos anos 70 surgem os primeiros cursos de pós-graduação em enfermagem no Rio de Janeiro e em São Paulo, com o objetivo de qualificar os profissionais para exercer a docência e a pesquisa nas universidades, faculdades e escolas espalhadas pelo país.

A década de 80 representa, no campo das políticas de saúde no Brasil, o momento de intenso debate sobre a crise sanitária do modelo médicoprivatista iniciada nos anos do processo de industrialização do país. Este modelo assistencial de saúde veio a substituir o sanitarismo campanhista vigente na época do Brasil agro-exportador ${ }^{(5,11)}$. Essas transformações ideológicas na conformação da política de saúde no país desencadearam o processo de discussão sobre as 'novas bases conceituais e metodológicas' que nortearia a formação de enfermagem a partir da década de 80 .

Anteriormente à promulgação da Constituição de 1988, entidades de classe, escolas e instituições de saúde discutiram a necessidade de reformulação dos currículos de 1972, pois o modelo assistencial em saúde estava mudando, o País passava por transformações de ordem social, era o fim da ditadura militar, uma nova ordem democrática iniciava-se. E o fato era que os profissionais formados até então não seriam capazes de atender às novas necessidades que eclodiam no setor saúde com o surgimento do Sistema Único de Saúde.

Nessa fase, a Associação Brasileira de Enfermagem-ABEN inicia processo de discussão sobre a formação em enfermagem e perspectivas das práticas curriculares projetadas para as escolas de enfermagem brasileiras. Um movimento democrático, que contou com a participação dos representantes das escolas, das instituições de saúde, das entidades de classe, dos movimentos sindicais e trabalhadores da enfermagem. Como resultado deste diálogo coletivo, em 1994, através da Portaria nº ${ }^{\circ}$ 1721/94 é oficializado o novo currículo para a enfermagem. Este prevê a formação do enfermeiro em quatro áreas: assistência, gerência, ensino e pesquisa ${ }^{(6,13)}$.

Logo em seguida ao movimento encabeçado pela ABEN sobre a reformulação do currículo mínimo de enfermagem, a Lei de Diretrizes e Bases da Educação Nacional-LDB - Lei ${ }^{\circ}$ 9.394, de 20 de dezembro de 1996 é oficializada; determinando mudanças na educação nacional, previa uma reestruturação dos cursos de graduação, iniciando pela extinção dos currículos mínimos e a adoção de diretrizes curriculares específicas para cada curso. Além de modificações no perfil do formando e nos compromissos das instituições de educação superior e docentes. Adaptando assim os cursos às mudanças do mercado de trabalho ${ }^{(6)}$.

Como resposta à adequação dos currículos de formação em saúde, no ano de 2001 são instituídas as DCN para os cursos de graduação da área da saúde, incluindo a Enfermagem. O desafio posto ao ensino de enfermagem na atualidade consiste em responder a questionamentos sobre como formar os futuros enfermeiros no Brasil, tendo como norte a LDB, as DCN, as transformações ideológicas do modelo 
assistencial proposto pelo SUS e as mudanças sócioeconômicas-culturais-éticas vivenciadas no mundo atual.

\section{O ENSINO DA ÉTICA E BIOÉTICA NA FORMAÇÃO DO ENFERMEIRO FRENTE ÀS DIRETRIZES CURRICULARES NACIONAIS}

As DCN para a enfermagem têm por objetivo direcionar as instituições educacionais de nível superior no Brasil na implantação dos seus respectivos Projetos Pedagógico, no caso da formação em enfermagem. A introdução da discussão da ética e da bioética nos cursos de formação não é uma prerrogativa exclusiva das Diretrizer Curriculares-DC ou do Código de Ética dos Profissionais de Enfermagem, que já aponta uma modificação do perfil do profissional graduado em enfermagem ${ }^{(14)}$.

Estudos anteriores $^{(1,6-15)}$ direcionam que o ensino da ética e da bioética tem a capacidade de desenvolver a moral refletida dos alunos de Enfermagem durante a graduação. Refletir sobre o cotidiano pluralista da sociedade humana atual traz à tona uma magnitude de problemas de saúde, de caráter tecnológico, humano, social, político e ético, que exige do profissional egresso dos cursos uma conduta moral mais consciente e autônoma, uma moral que vá além das normas impostas tradicionalmente por uma ética pautada em determinar regras e doutrinas a serem seguidas.

Nós, como formadores dos profissionais de enfermagem, temos de ter em mente que o conhecimento teórico das DC é imprescindível, pois possibilita a adesão destas às propostas dos Projetos Pedagógicos dos Cursos-PPC construídos pelas IES do País. A adesão a esses projetos educacionais tem por obrigatoriedade vislumbrar a produção do trabalho interdisciplinar em saúde e enfermagem pautada na ação do cuidado integral, na construção de uma moral refletida dos alunos da graduação, promovendo a sua capacidade de intervir positivamente na vida dos sujeitos construídos na sua dimensão individual e coletiva.

Assim, autores discorrem sobre as DC para o ensino da ética e da bioética na graduação em Enfermagem, e mais, colocam a importância da introdução dessa discussão nos PPC das IES. Concluem que a implantação desse discurso na educação profissional dos alunos da enfermagem consiste num desafio devido à diversidade cultural e moral existente no mundo atual ${ }^{(1,15)}$. Estas diretrizes, portanto, constituem uma superestrutura política e ideológica que direciona a formação dos profissionais da área, compreendidos como trabalhadores do SUS. Colocam que o caminho da construção dos currículos percorridos pelas IES é diferenciado e que a determinação deste processo de construção e reconstrução da educação em enfermagem ocorre a partir dos contextos históricos. As DC têm por meta conferir autonomia às IES sobre os projetos pedagógicos conformados por marcos teóricos-metodológicos definidos coletivamente ${ }^{(15)}$.

Retomando outro estudo ${ }^{(1)}$, este propõe que o ensino da ética e da bioética seja transversal ao processo de formação do enfermeiro e que a prática docente seja capaz de ajudar o aluno a analisar criticamente a realidade e que este analise os problemas práticos da saúde-doença no cotidiano das pessoas. Outra proposta é a de que as normas sirvam de norte para a tomada de decisões que porventura os futuros enfermeiros venham a tomar no seu trabalho, com a ressalva de que essas decisões não tenham seu fim no caráter normativo da ética.

\section{CONSIDERAÇÕES FINAIS}

Ao refletir teoricamente sobre o ensino da ética e da bioética, entendemos que a construção de um novo conhecimento, competências, atitudes e habilidades no exercício profissional da enfermagem devem ter por fundamentação teórica as concepções da ciência ética e da bioética, no que diz respeito à construção da consciência moral refletida e vivida dos alunos da graduação frente à pluralidade social e cultural dos homens em sociedade.

Pensar uma prática docente voltada à incorporação dos saberes da ética e da bioética frente às DCN requer o rompimento das concepções tradicionais que reduzem a ética ao campo normativo da conduta humana, bem como a capacitação dos professores nesse campo do conhecimento.

Em se tratando da construção do PPC, é necessário que todos os envolvidos com o processo de formação adotem uma postura participativa e de mudança que busque a adequação do Projeto às DC, favorecendo assim a formação de enfermeiros críticos e reflexivos da sua prática social, o que na atualidade se configura como um desafio possível de ser alcançado somente a partir do pensamento coletivo de indivíduos comprometidos com a formação nas Instituições de Educação Superior da Enfermagem.

Portanto, trabalhar a relação entre Currículo, Enfermagem, Ética e Bioética requer conhecimentos 
teóricos e metodológicos por parte dos docentes. Estes devem ter ao seu alcance meios e instrumentos para o desenvolvimento do seu trabalho educacional. Assim, a formação dos enfermeiros se norteará pelos modelos de assistência na saúde individual e coletiva vigente e no conhecimento disciplinar produzido. Busca-se com o ensino da ética e da bioética, corroborando com os estudos anteriores ${ }^{(1,6-15)}$, a qualificação por competências do aluno da graduação frente às diversas formas de organização do trabalho e dos trabalhadores de saúde, em especial da enfermagem, assim como o reconhecimento pelos discentes das relações desses profissionais com os usuários do SUS.

O aluno da graduação precisa compreender que os problemas práticos da saúde ocorrem em meio à diversidade sócio-histórico-cultural dos homens e que discutir o exercício profissional da enfermagem à luz da ética é possibilitar ao egresso/profissional a capacidade de agir conscientemente de forma crítica e refletida. Ao docente, cabe o papel de ser o facilitador dessa formação, pautado nos problemas práticos que se apresentam no cotidiano profissional da saúde e da enfermagem. Além disso, no processo de planejamento do ensino, é preciso que eles tenham as Diretrizes Curriculares como norte da sua prática, promovendo dessa forma a adesão dos currículos.

\section{REFERÊNCIAS}

1. Ferreira HM, Ramos LH. Diretrizes curriculares para o ensino da ética na graduação em enfermagem. Acta Paul Enferm. 2006;19(3):329-31.

2. Vásquez AS. Ética. $28^{a}$ ed. Rio de Janeiro: Civilização Brasileira; 2006.

3. Chiattone HBC, Sebastiani RW. Ética em saúde algumas reflexões sobre nossos desafios para o Século XXI. In. Angerami VA, organizadora. Aética na saúde. São Paulo: Pioneira; 1997: 175-82.

4. Ministério da Educação (BR). Secretaria de Educação Superior. Diretrizes Curriculares para os Cursos de Graduação. Resolução CNE/CES Nº. 3, de 7 de Novembro de 2001 [on line]. [acesso em 2008 Jul 11] Disponível: http://portal. mec.gov.br/cne/arquivos/pdf/ CES03.pdf.

5. Ministério da Saúde (BR). O Sistema Público de Saúde Brasileiro. Brasília: Ed. Ministério da Saúde, 2002. [on line]. [acesso em 2008 Jul 10].Disponível: http://bvsms. saude.gov.br/bvs/publicacoes/sistema_saude.pdf
6. Ito EE, Peres AM, Takahashi RT, Leite MMJ. O ensino de enfermagem e as diretrizes curriculares nacionais: utopia x realidade. Rev Esc Enferm USP. 2006;40(4):570-5.

7. Minayo MCS. O desafio do conhecimento: pesquisa qualitativa em saúde. $9^{a}$ ed. Rio de Janeiro: HUCITEC; 2006.

8. Triviños ANS. Introdução a pesquisa em ciências sociais: a pesquisa qualitativa em educação. São Paulo: ATLAS; 1987.

9. Almeida MCP, Rocha JSY. O saber de enfermagem e sua dimensão prática. 2ª ed. São Paulo: Cortez; 1989.

10. Luz TM. Notas sobre políticas de saúde no Brasil de 'transição democrática - anos 80. Physis. Rev Saúde Col.1991;1(1)132-154.

11. Paixão W. História de enfermagem. $5^{\mathrm{a}}$ ed. Rio de Janeiro: Júlio C. Reis; 1979.

12. Barros ME, Piola SF, Vianna SM. Política de saúde no Brasil: diagnóstico e perspectivas. Brasília: IPEA; 1996.

13. Lima MADS. Ensino de enfermagem: retrospectiva, situação atual e perspectivas. Rev Bras Enferm. 1994;47(3):270-7.

14. Rio Grande do Norte. Conselho Regional de Enfermagem. Legislação básica para o exercício profissional da enfermagem. Natal: Opção Gráfica; 2007.

15. Santana FR, Nakatani AYK, Souza ACS, Casagrande LDR, Espiridião E. Diretrizes curriculares nacionais do curso de graduação em enfermagem: uma visão dialética. [periódico na Internet] Revista Eletrônica de Enfermagem. 2005 [acesso em 2008 Jul 11] 7 (3):294-300. Disponível: http://www.fen.ufg.br/revista/revista7_3/ original_06.htm. 